\title{
Excess length of stay and economic consequences of adverse events in Dutch hospital patients
}

Janneke Hoogervorst-Schilp ${ }^{1 *}$, Maaike Langelaan ${ }^{1}$, Peter Spreeuwenberg ${ }^{1}$, Martine C. de Bruijne ${ }^{2}$ and Cordula Wagner ${ }^{1,2}$

\begin{abstract}
Background: To investigate the average and extrapolated excess length of stay and direct costs of adverse events (AEs) and preventable AEs in Dutch hospitals, and to evaluate patient characteristics associated with excess length of stay and costs.

Methods: Data of a large retrospective patient record review study on AEs was used. A stratified sample of 20 Dutch hospitals was included. Excess length of stay and costs attributable to AEs and preventable AEs were calculated and extrapolated to a national estimate. The association between patient characteristics and excess length of stay (and costs thereof) attributable to AEs and preventable AEs was investigated through multilevel linear regression analyses.

Results: A total of 2975 patient records were included in the analysis, of which 325 experienced one or more AEs. Hospital patients experiencing an AE stayed 5.11 (95\% Cl 3.91-6.30) more days in hospital and cost €2600 (95\% Cl $€ 1968-€ 3232)$ more compared to those without an AE. There was no significant difference in days and costs between preventable and non-preventable AEs. Extrapolated to a national level, AEs cost more than $€ 300$ million, which was $1.3 \%$ of the national hospital care budget. Patients with hospital-acquired infections had a statistically significant longer length of stay compared to the reference group (patients with AEs on the cardiovascular system).

Conclusions: This study showed that AEs lead to substantial excess length of stay and increased costs. Special attention should be paid to patients with AEs due to an hospital-acquired infection.
\end{abstract}

Keywords: Adverse event, Excess length of stay, Costs, Hospital

\section{Background}

An $\mathrm{AE}$ is defined as an unintended injury that results in temporary or permanent disability, death or prolonged hospital stay, and is caused by healthcare management rather than by the patient's underlying disease process [1]. Between 2.9 and $16.6 \%$ of hospital patients experienced an AE during their hospital admission [1-8]. Several studies showed that AEs are associated with longer hospital length of stay (LOS). Excess LOS attributable to AEs ranges from 6 to 9 days [9-14], leading to higher healthcare costs [15-25]. Earlier studies investigating excess LOS and associated costs of AEs were mostly limited

\footnotetext{
* Correspondence: jannekeschilp@hotmail.com

${ }^{1}$ NIVEL, Netherlands Institute for Health Services Research, PO Box 1568, 3500 BN, Utrecht, The Netherlands

Full list of author information is available at the end of the article
}

to AEs caused by medication errors [15, 19, 23-25], or investigated only costs associated with specific diseases or treatment $[17,21,22]$. In the Netherlands, total direct medical costs of AEs in hospitals were estimated using patient records of 2004 [18]. The total annual direct medical costs were estimated at $€ 355$ million for all AEs. Since 2004, much has changed in the Dutch healthcare system and utilisation of hospital care. Diagnosis Related Groups (DRG's) were introduced in hospital care in 2005 to improve transparency and quality, by defining products which can be negotiated between purchasers and providers of care. The total hospital care costs rose from $€ 15.5$ billion in 2004 to $€ 23.9$ billion in 2012, forcing hospitals to reduce healthcare costs. Since the major part of the direct medical costs in hospitals due to an AE consists of excess LOS [18], insight into the excess LOS and costs associated with AEs 
is essential for determining economic consequences of AEs and preventable AEs. This information may support hospitals in justifying their investments in patient safety interventions that will both improve patients' health and reduce avoidable health system costs.

Besides the economic consequences of AEs, information should also be available about the patient's characteristics contributing to a longer LOS and higher costs if an $\mathrm{AE}$ occurs. An earlier study showed that poorer health status during admission was associated with increased AEs, and also with increased costs and LOS [26]. The study of Hoonhout et al. showed which determinants influenced the costs attributable to AEs in 2004.

The aim of this study is to investigate the average and extrapolated excess LOS and direct costs of AEs and preventable AEs in Dutch hospitals. Furthermore, patient characteristics associated with excess LOS and costs due to AEs and preventable AEs will be evaluated.

\section{Methods}

\section{Design and setting}

For the present study, data of a large retrospective patient record review study was used. This study was performed in a random sample of 20 Dutch hospitals, stratified by hospital type and location (urban or rural). Eligible hospitals had at least 200 beds, an emergency department and an intensive care unit. A total of four university-, eight tertiary teaching- and eight general hospitals were included in the sample. Tertiary teaching hospitals in The Netherlands provide specialised care and train doctors. The complexity of care given is between that given in a university hospital and in a general hospital. In each participating hospital, 200 patient admissions between April 1st 2011 and March 31st 2012 were randomly selected A large subsample $(50 \%$ of the sample) of hospital patients who died in hospital during admission, was included. This made it possible to estimate the number of preventable deaths in the primary study as this is a relatively small patient group. These patients were sampled from all inpatient deaths The random sampling was performed by giving random numbers to eligible patients (with Excel) and to include number 1-100 of the deceased patients and number 1-100 of the alive patients. Patients admitted to the psychiatry department, obstetrics and children $<1$ year old were excluded. More details about the design and methods of the study have been described elsewhere [27].

\section{Patient record review}

The nursing, medical, and - if available - outpatient records of the sample patient admissions were reviewed by 34 trained external nurses and 17 trained external medical specialists (eight internists, seven surgeons and two neurologists) in a two-stage review process. The method of determining AEs was comparable to those of other international studies [2, 3]. In the first stage a nurse screened the records by using 16 triggers indicating potential AEs. In the second phase, admissions positive for at least one trigger were further reviewed by a physician. Based on a standardised procedure, and preceded by a number of underlying questions to secure a systematic assessment, the presence and preventability of an $\mathrm{AE}$ was determined. An AE was defined by three criteria:1) an unintended (physical and/or mental) injury which results in; 2) prolonged hospital stay, temporary or permanent disability or death; and 3) is caused by healthcare management rather than the patient's condition.

$\mathrm{An} \mathrm{AE}$ was found to be preventable when the care given fell below the current level of expected performance for practitioners or systems. The cause and preventability of AEs were scored on a six-point Likert scale. A score of 4-6 indicated that the reviewer regarded the event as having a greater than $50 \%$ chance of being caused by healthcare, or was preventable, and was considered as $\mathrm{AE}$.

The AEs that occurred during the patient's index hospital admission and were detected during either the index admission or subsequent admissions over the following 12month period were counted. AEs related to patient admissions in the same hospital within the 12 months preceding the index admission, but which were not detected until the index admission were also counted. Consequently, patient records of the index hospital admission were reviewed, as were the patient records of patient admissions before and after the index admission.

Additional data on the total Dutch hospital population in 2011/2012 and administrative hospital information for the reviewed patient admissions was collected from the national hospital administration database (LMR) maintained by Dutch Hospital Data.

\section{Excess length of stay}

Within the LMR, for each hospital admission, the expected LOS was computed. This calculation was based on characteristics of the patients and the national mean LOS that is associated with these characteristics [28]. The following characteristics of the patients were taken into account:

- Age, divided into four classes: 1-14, 15-44, 45-64, $65+$ years

- The primary diagnosis that resulted in the admission, including about 1,000 diagnoses classified by the ICD9 in three digits

- Procedures, classified by the Dutch Classification System of Procedures. The procedures considered depend on the diagnosis of the patient.

Normally these calculations were only used for patients discharged alive, but for the purpose of this study the 
expected LOS was also calculated for the patients which died in hospital. The excess LOS during the index admission was calculated by subtracting the expected LOS from the actual observed LOS, using the LMR data. If expected LOS in was missing within the LMR, the excess LOS was imputed by estimations of extra hospital days due to an $\mathrm{AE}$ indicated by the reviewer during the second stage of the study. The estimates of excess LOS varied from no extra bed days to all bed days of the index admission. For re-admissions attributable to AEs during the index admission, we imputed the national average hospital stay in 2012 (5.3 days).

\section{Costs of excess LOS}

To estimate direct costs of excess LOS, the calculated excess LOS during index admission and re-admission was multiplied by unit costs. The costs of one extra hospital admission day was valued by the Dutch guideline prices of 2009 [29]. Only guideline prices for university and general hospitals were available. For tertiary medical teaching hospitals, guideline prices for general hospitals were used. The unit costs include costs of a standard hospital day, medical and nursing staff, medication, material, equipment, housing and overhead. After correction with price indices for 2012 , the unit costs per day were $€ 461.83$ for generaland tertiary medical teaching hospitals and $€ 610.46$ for university hospitals. The unit costs per day were $€ 2317.63$ for intensive care units (ICUs).

\section{Potential determinants}

Several patient characteristics were investigated as potential determinant for excess LOS and costs due to AEs and preventable AEs. Age (in years), sex, urgent admission (yes/no), and specialty (surgery versus nonsurgery) were collected within the patient record review. ICD9 diagnostic information was gathered from the LMR data and used to define diagnostic groups. The following diagnostic groups were defined: neoplasm, endocrine, nutritional and metabolic diseases, cardiovascular diseases, respiratory system, digestive system, genitourinary system, symptoms, signs and ill-defined conditions, and injury and poisoning. All other diagnostic codes were defined as 'all other codes'.

Besides patient characteristics, type of $\mathrm{AE}$ was also investigated as potential determinant for excess LOS and costs due to AEs and preventable AEs.

\section{Statistical analysis}

The mean excess LOS and costs attributable to AEs and preventable AEs with $95 \%$ confidence intervals (CIs) were estimated using multilevel linear regression analyses. A two-level multilevel structure was used, whereby the observations were clustered within hospitals. The national estimate of excess LOS and costs attributable to AEs in
2011/2012 was calculated by multiplying total amount of Dutch hospital admissions in the period April 1st 2011 and March 31st $2012(n=1.678 .283)$ with AE rate $(7.1 \%)$ [30] and by subsequently multiplying this with the extra costs of an AE. The calculation was repeated for costs of preventable AEs ( $1.6 \%$ preventable AE rate).

Multilevel linear regression analyses were performed to investigate the association between patient characteristics and excess LOS attributable (and the costs thereof) to AEs and preventable AEs. The dependent variable in the model was either the excess LOS or the costs of excess LOS. The independent variable was either AE or preventable AE. The determinants were added as covariates to the models. The variables included in the model were centred to reference values for all Dutch hospital admissions in 2011/2012. The variables 'type of $A E^{\prime}$ ' and 'diagnostic groups' were centred to the mean of these variables in the total sample.

The amount of variation in excess LOS and costs of AEs and preventable AEs caused by hospital level was indicated by the Intraclass Correlation Coefficient (ICC) [31]. The ICC is the ratio of between-group variance and total variance, whereby a higher ICC represents a larger variance between hospitals in $\mathrm{AE}$ rates and a smaller variance within hospitals.

An additional analysis was performed to investigate the costs of excess LOS including ICU days, as the costs of ICU days are much higher compared to the costs of a normal hospital day. ICU costs were not included in the main analysis, because we had no information about the exact number of ICU days caused by the AE. For patients admitted to the ICU during their index admission, the number of days in ICU or intermediate care, reported in the first stage of the review process, was multiplied by unit costs of an ICU day. The remaining days of the excess LOS were multiplied by unit costs per day for the specified hospital type.

In all multilevel analyses, corrections were made for overrepresentation of patients admitted to a university hospital and for overrepresentation of patients who died in hospital by adding these covariates to the model. Descriptive analyses were performed using Stata 13.0. Multilevel analyses were performed using MLwiN version 2.24 (University of Bristol, 2011). For all analyses, $p$-values $\leq .05$ were considered statistically significant.

\section{Results}

During the first stage, a total of 4048 patient records were reviewed by nurses. In the present study, patient records with missing data for both expected LOS in the LMR data and estimations of excess LOS by the reviewer during the second stage of the study $(n=915)$ and with missing data on any of the potential determinants for excess LOS $(n=22)$ were excluded, resulting in a sample 
of 3111 patient records. LOS was imputed for 142 patient records $(4.5 \%)$ by the estimations indicated by the reviewer. During the second stage, physicians identified one or more AEs in 348 of these 3111 reviewed patient admissions. For patients with multiple AEs, only records with the first reported AEs $(N=325)$ were included in the analysis, resulting in a total sample of 2975 patient records. AEs were found to be preventable in 89 of the 325 patient records. These numbers are unweighted.

\section{Excess LOS and costs of (preventable) AEs}

Table 1 shows mean excess LOS and costs attributable to AEs following from the multilevel linear regression analyses. The LOS of patients experiencing an AE was 5.11 days (95 \% CI 3.91-6.30) longer compared to patients without an AE. The mean extra costs of LOS were $€ 2600$ (95\% CI 1968-3232) higher for patients experiencing an AE compared to those without an AE. There was no statistically significant difference (mean difference 2.33 days; $95 \%$ CI -1.19-5.85) in LOS between preventable and non-preventable AEs. There was no statistically significant difference (€1021; $95 \%$ CI -775-2817) in costs between preventable AE and non-preventable AEs.

Extrapolating differences in costs due to an AE resulted in an estimate of $€ 309,812,233$ extra costs attributable to AEs in the Netherlands in 2011/2012. This was $1.3 \%$ of the national hospital care budget ( $€ 23.9$ million) in 2012 . Per 100,000 patient admissions, the estimated extra costs attributable to AEs were $€ 18,460,071$.

During the index admission, patients experiencing an $\mathrm{AE}$ were more often admitted to intensive care or intermediate care (45.5\%) compared to those without an AE (21.0\%). The additional multilevel analysis showed a larger difference in costs (€6038; $95 \%$ CI 4543-7533) between those experiencing AEs compared to those without AEs when the ICU costs were included. There was no statistically significant difference (€2464; $95 \%$ CI -2301-7230) in costs between preventable AEs and non-preventable AEs.

\section{Determinants of excess LOS and costs}

Table 2 shows the results of the multilevel linear regression analysis of excess LOS and costs due to AEs. Excess LOS differed statistically significantly between different types of AE. Patients with a hospital-acquired infection had a statistically significant longer excess LOS of 4.7 days and $€ 2337$ higher costs compared to those with AEs on the cardiovascular system. The costs of the excess LOS due to AEs were $€ 537$ lower for urgent admissions compared to those for planned admissions. No other statistically significant determinants were found.

The multilevel analysis of excess LOS and costs due to preventable AEs showed no statistically significant determinants for excess LOS due to preventable AEs compared to non-preventable AEs (table not shown).

\section{Variation in excess LOS and costs}

The variation in excess LOS was not caused by hospital level as the ICC was 0.05 for AEs and 0.00 for preventable AEs. A comparable result was found for variation in costs, the ICC was 0.01 for AEs and 0.00 for preventable AEs. This means that at most only $5 \%$ of the variance in excess LOS and costs was caused by differences in the investigated determinants between individual hospitals. The remaining variance is caused by differences in other characteristics such as patient characteristics, organisation characteristics, medical staff characteristics, technology characteristics, or environment.

\section{Discussion}

The results of our study showed that patients experiencing an AE during hospitalisation stay five days longer in hospital and cost $€ 2600$ more compared to those not experiencing an AE. Extrapolation of our results showed that total costs of excess LOS due to AEs was more than $€ 300$ million in Dutch hospitals in $2011 / 2012$. This was $1.3 \%$ of the Dutch national hospital care budget in 2012 . AEs concerning hospital-acquired infections contributed to longest excess LOS and highest costs. Urgently admitted

Table 1 Mean excess LOS and costs of AEs and preventable AEs in the Netherlands in 2011/2012

\begin{tabular}{|c|c|c|c|c|}
\hline & $N$ & $\begin{array}{l}\text { Mean excess LOS in days } \\
(95 \% \mathrm{Cl})\end{array}$ & $\begin{array}{l}\text { Mean costs of excess } \\
\text { LOS in } €(95 \% \mathrm{Cl})\end{array}$ & $\begin{array}{l}\text { Sensitivity analysis mean costs of excess } \\
\text { LOS in } €(95 \% \mathrm{Cl})^{c}\end{array}$ \\
\hline \multicolumn{5}{|c|}{$\mathrm{AE}(N=2975)$} \\
\hline No & 2650 & $2.43(1.51-3.35)$ & $1085(695-1475)$ & $1084(354-1814)$ \\
\hline Yes & 325 & $7.53(6.12-8.94)^{* * *}$ & $3685(2992-4378)^{* * *}$ & $7122(5577-8667)^{* * *}$ \\
\hline \multicolumn{5}{|c|}{ Preventable $\mathrm{AE}(\mathrm{N}=325)^{\mathrm{b}}$} \\
\hline No & 236 & $7.94(5.28-10.60)$ & $3906(2580-5233)$ & $4982(1479-8484)$ \\
\hline Yes & 89 & $10.26(6.52-14.00)$ & $4927(3034-6821)$ & 7446 (2449-12443) \\
\hline
\end{tabular}

$A E$ adverse event, LOS length of stay; ${ }^{* * *} P<0.001$

${ }^{a}$ In all multilevel linear regression analyses mean excess LOS were corrected for overrepresentation of patients admitted to a university hospital and of deceased patients

${ }^{\mathrm{b}}$ Number of patients experiencing an $\mathrm{AE}$

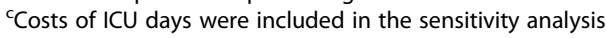


Table 2 Multilevel regression analysis of the excess LOS and costs of AEs $(N=2975)$

\begin{tabular}{|c|c|c|c|c|c|}
\hline & \multicolumn{5}{|l|}{$A E$} \\
\hline & \multirow[t]{2}{*}{$\overline{N(\%)}$} & \multicolumn{2}{|c|}{ Excess LOS } & \multicolumn{2}{|l|}{ Costs } \\
\hline & & Days & SE & $\bar{€}$ & SE \\
\hline$\overline{A E}(r e f=n o A E)$ & 325 & $5.03^{* * *}$ & 0.62 & $2536^{* * *}$ & 192 \\
\hline Age & & -0.003 & 0.01 & -3 & 6 \\
\hline Sex $(r e f=$ men $)$ & $1555(52)$ & 0.26 & 0.38 & 163 & 200 \\
\hline Urgent admission (reference $=$ no) & $2073(70)$ & -0.70 & 0.49 & $-537^{*}$ & 262 \\
\hline Surgery specialty (ref = non-surgery) & $976(33)$ & -0.67 & 0.48 & -385 & 253 \\
\hline \multicolumn{6}{|l|}{ Type of AE (ref = cardiovascular system) } \\
\hline Respiratory system & 34 & 0.18 & 2.55 & 225 & 1355 \\
\hline Renal system & 29 & -0.14 & 2.64 & -78 & 1401 \\
\hline Haematological system & 20 & 2.27 & 2.89 & 1494 & 1536 \\
\hline Gastrointestinal event & 30 & -1.15 & 2.58 & -706 & 1370 \\
\hline Neurological system & 18 & -3.32 & 2.94 & -1653 & 1563 \\
\hline Hospital-acquired infection & 79 & $4.70^{*}$ & 2.08 & $2337^{*}$ & 1104 \\
\hline Surgical or obstetric event & 76 & 2.04 & 2.09 & 956 & 1112 \\
\hline Other type of $A E$ & 23 & 4.71 & 2.74 & 2415 & 1457 \\
\hline \multicolumn{6}{|l|}{ Diagnostic groups $($ ref $=$ infection diseases $)$} \\
\hline Neoplasm & $515(17)$ & 0.71 & 1.12 & 317 & 594 \\
\hline Endocrine, nutritional and metabolic diseases & $57(2)$ & -0.18 & 1.70 & -205 & 902 \\
\hline Cardiovascular diseases & $759(26)$ & -1.06 & 1.09 & -595 & 577 \\
\hline Respiratory system & $309(10)$ & 0.10 & 1.17 & 56 & 622 \\
\hline Digestive system & $276(9)$ & 1.29 & 1.20 & 781 & 637 \\
\hline Genitourinary system & $147(5)$ & -0.45 & 1.34 & -311 & 710 \\
\hline Symptoms, signs and ill-defined conditions & $152(5)$ & 0.29 & 1.31 & 156 & 698 \\
\hline Injury and poisoning & $266(9)$ & 0.14 & 1.22 & 141 & 648 \\
\hline All other codes & $494(17)$ & -0.09 & 1.17 & -112 & 623 \\
\hline ICC ${ }^{a}$ hospital level (\%) & & $5.0 \%$ & & $0.01 \%$ & \\
\hline
\end{tabular}

$A E$ adverse event, LOS length of stay, SE Standard Error, $\beta$ difference; ${ }^{*} P<0.05 ;{ }^{* * *} P<0.001$

${ }^{a}$ Intraclass correlation (ICC) is the ratio of the between-group variance and the total variance

patients had lower costs of excess LOS due to AEs compared to planned admissions. No statistically significant difference in days and costs was found between preventable and non-preventable AEs.

The mean excess LOS due to AEs was slightly lower compared to results of previous studies in hospital patients. Naessens et al. found a difference in excess LOS of 8.6 days between hospital patients with and without an $\mathrm{AE}$ [26]. Ehsani et al. found a difference of 7.0 days between patients with acute admission for cardiac disease experiencing AEs and those without AEs [16]. The costs of excess LOS investigated in these two studies could not be compared to our results, as they estimated total costs of patients from hospital costing systems. Other recent studies considering costs of LOS investigated only excess LOS due to adverse drug events, and could therefore not be compared to our results $[15,19,24]$. Compared to the results of 2004 [18], the excess LOS was almost half of the days (5.1 compared to 9.1 days). A reduction could have been expected, as there was a nationwide downward trend in mean hospital LOS in the last decade, from 7.3 days in 2004 to 5.3 days in 2012. Possibly, increased awareness and earlier recognition of consequences of AEs among healthcare providers contributed to more rapid action being taken.

Following the results of our study, patients with hospitalacquired infections had a statistically longer LOS and higher costs. This is in line with an observational study in hospital patients, showing that a hospital-acquired infection with Clostridium difficile increased the medium LOS by 6 days [32]. Implementation of possibilities for preventing these infections should be investigated, for example improving hand hygiene [33]. Urgently admitted patients had lower costs attributable to AEs compared to planned admissions. This might be the result of differences in the 
percentage of urgent admissions between hospital types: in the more expensive academic hospitals fewer patients were urgently admitted (59\%) compared to tertiary medical teaching hospitals (71 \%) and general hospitals (75 \%).

An important strength of this study is that complete patient admissions have been reviewed independently by qualified nurses and physicians in a structured manner to ascertain AEs. Another strength is the large sample of hospitals and stratification by hospital type and location, which enabled extrapolation of the results to a national level.

Some limitations of our study have to be mentioned. Despite the correction for the overrepresentation of deceased patients, the calculated excess LOS might be slightly overestimated. Deceased patients are probably more severe patients compared to the discharged patients. An additional analysis showed that the deceased patients had a statistically significant $(P<0.001)$ longer excess LOS of 1.67 days (95\% CI $0.88-2.45$ ) compared to the discharged patients. The calculated costs of AEs in our study were presumably an underestimation of the total costs within hospitals caused by AEs, because only costs of excess LOS were included. Costs of extra medical procedures attributable to AEs could not be taken into account as the registration of these procedures was poor. This is a result of the system (Diagnosis-related group, DRG), which reimburses hospitals based on fixed prices for a combination of diagnosis and treatment, whereby procedures are not declared individually. Hereby, the results of our study could not be compared directly to other countries with different health care and cost systems. The method used for calculating excess LOS (observed LOS minus expected LOS) may also have contributed to an underestimation of the excess LOS [28]. However, this was the most accurate available method to approach excess LOS due to an AE. From a societal perspective, outpatient healthcare, productivity loss and loss of income could also be important, as are the potential costs for medical claims after an AE occurred. However, these outcomes could not be taken into account in our study. Despite these limitations in calculating excess LOS, our study showed that AEs leads to substantial excess LOS and costs.

\section{Conclusions}

This study showed that AEs leads to substantial excess LOS and increased costs. No statistically significant difference was found in excess LOS and costs between preventable and non-preventable AEs. Extrapolating the results showed that the total costs of excess LOS due to AEs in Dutch hospitals was more than $€ 300$ million in $2011 / 2012$. These costs were approximately $1.3 \%$ of the national hospital care costs. Since patients with AEs due to an hospital-acquired infection had a large increase of excess LOS, special attention should be paid to these.

\section{Abbreviations}

AE: Adverse event; LOS: Length of stay; ICU: Intensive care unit;

Cl: Confidence interval; ICC: Intraclass Correlation Coefficient.

\section{Competing interests}

None of the authors have competing interest to declare.

\section{Authors' contributions}

JS carried out the statistical analysis, interpreted the data, and drafted the manuscript; ML participated in the design and coordination of the study, and interpreted the data; PS carried out the statistical analysis and interpreted the data; MdB participated in the design of the study; CW participated in the design of the study and interpreted the data. All authors read and approved the final version.

\section{Acknowledgement}

We would like to thank everyone who contributed to the study, especially the nurses and doctors who reviewed the patient records, and the participating hospitals, including their staff who facilitated the patient records.

\section{Author details}

${ }^{1}$ NIVEL, Netherlands Institute for Health Services Research, PO Box 1568, 3500 BN, Utrecht, The Netherlands. ${ }^{2}$ Department of Public and Occupational Health \& EMGO Institute for Health and Care Research, VU University Medical Centre, Van der Boechorststraat 7, 1081 BT, Amsterdam, The Netherlands.

Received: 10 April 2015 Accepted: 30 November 2015

Published online: 01 December 2015

\section{References}

1. Zegers M, de Bruijne MC, Wagner C, Hoonhout LH, Waaijman R, Smits M, et al. Adverse events and potentially preventable deaths in Dutch hospitals: results of a retrospective patient record review study. Qual Saf Health Care. 2009;18(4):297-302.

2. Baker GR, Norton PG, Flintoft V, Blais R, Brown A, Cox J, et al. The Canadian Adverse Events Study: the incidence of adverse events among hospital patients in Canada. Cmaj. 2004;170(11):1678-86.

3. Brennan TA, Leape LL, Laird NM, Hebert L, Localio AR, Lawthers AG, et al. Incidence of adverse events and negligence in hospitalized patients: results of the Harvard Medical Practice Study I. 1991. Qual Saf Health Care. 2004; 13(2):145-51. discussion 151-142.

4. Davis P, Lay-Yee R, Briant R, Ali W, Scott A, Schug S. Adverse events in New Zealand public hospitals I: occurrence and impact. N Z Med J. 2002; 115(1167):U271.

5. Soop M, Fryksmark U, Koster M, Haglund B. The incidence of adverse events in Swedish hospitals: a retrospective medical record review study. Int J Qual Health Care. 2009;21(4):285-91.

6. Vincent C, Neale G, Woloshynowych M. Adverse events in British hospitals: preliminary retrospective record review. BMJ. 2001;322(7285):517-9.

7. Thomas EJ, Studdert DM, Burstin HR, Orav EJ, Zeena T, Williams EJ, et al. Incidence and types of adverse events and negligent care in Utah and Colorado. Med Care. 2000;38(3):261-71.

8. Wilson RM, Runciman WB, Gibberd RW, Harrison BT, Newby L, Hamilton JD. The quality in Australian health care study. Med J Aust. 1995;163(9):458-71.

9. Ackroyd-Stolarz S, Read Guernsey J, Mackinnon NJ, Kovacs G. The association between a prolonged stay in the emergency department and adverse events in older patients admitted to hospital: a retrospective cohort study. BMJ Qual Saf. 2011;20(7):564-9.

10. Cihangir S, Borghans I, Hekkert K, Muller H, Westert G, Kool RB. A pilot study on record reviewing with a priori patient selection. BMJ Open. 2013;3:7.

11. Forster AJ, Kyeremanteng K, Hooper J, Shojania KG, van Walraven C. The impact of adverse events in the intensive care unit on hospital mortality and length of stay. BMC Health Serv Res. 2008;8:259.

12. Hoonhout LH, de Bruijne MC, Wagner C, Asscheman H, van der Wal G, van Tulder MW. Nature, occurrence and consequences of medication-related adverse events during hospitalization: a retrospective chart review in the Netherlands. Drug Saf. 2010;33(10):853-64.

13. Ricciardi R, Roberts PL, Read TE, Hall JF, Marcello PW, Schoetz DJ. Which adverse events are associated with mortality and prolonged length of stay following colorectal surgery? J Gastrointest Surg. 2013;17(8):1485-93. 
14. Sari AB, Sheldon TA, Cracknell A, Turnbull A, Dobson Y, Grant C, et al. Extent, nature and consequences of adverse events: results of a retrospective casenote review in a large NHS hospital. Qual Saf Health Care. 2007;16(6):434-9.

15. Classen DC, Pestotnik SL, Evans RS, Lloyd JF, Burke JP. Adverse drug events in hospitalized patients. Excess length of stay, extra costs, and attributable mortality. JAMA. 1997;277(4):301-6.

16. Ehsani JP, Duckett SJ, Jackson T. The incidence and cost of cardiac surgery adverse events in Australian (Victorian) hospitals 2003-2004. Eur J Health Econ. 2007;8(4):339-46.

17. Hellsten EK, Hanbidge MA, Manos AN, Lewis SJ, Massicotte EM, Fehlings $M G$, et al. An economic evaluation of perioperative adverse events associated with spinal surgery. Spine J. 2013;13(1):44-53.

18. Hoonhout LH, de Bruijne MC, Wagner C, Zegers M, Waaijman R, Spreeuwenberg $P$, et al. Direct medical costs of adverse events in Dutch hospitals. BMC Health Serv Res. 2009;9:27.

19. Hug BL, Keohane C, Seger DL, Yoon C, Bates DW. The costs of adverse drug events in community hospitals. Jt Comm J Qual Patient Saf. 2012;38(3):120-6.

20. Kaushal R, Bates DW, Franz C, Soukup JR, Rothschild JM. Costs of adverse events in intensive care units. Crit Care Med. 2007;35(11):2479-83.

21. Kessler ER, Shah M, Gruschkus SK, Raju A. Cost and quality implications of opioid-based postsurgical pain control using administrative claims data from a large health system: opioid-related adverse events and their impact on clinical and economic outcomes. Pharmacotherapy. 2013;33(4):383-91.

22. Kim MH, Lin J, Hussein M, Battleman D. Incidence and economic burden of suspected adverse events and adverse event monitoring during AF therapy. Curr Med Res Opin. 2009;25(12):3037-47.

23. Oderda GM, Evans RS, Lloyd J, Lipman A, Chen C, Ashburn M, et al. Cost of opioid-related adverse drug events in surgical patients. J Pain Symptom Manage. 2003;25(3):276-83

24. Rottenkolber D, Hasford J, Stausberg J. Costs of adverse drug events in German hospitals-a microcosting study. Value Health. 2012;15(6):868-75.

25. Schneider PJ, Gift MG, Lee YP, Rothermich EA, Sill BE. Cost of medicationrelated problems at a university hospital. Am J Health Syst Pharm. 1995: 52(21):2415-8

26. Naessens JM, Campbell CR, Shah N, Berg B, Lefante JJ, Williams AR, et al. Effect of illness severity and comorbidity on patient safety and adverse events. Am J Med Qual. 2012;27(1):48-57.

27. Baines R, Langelaan M, de Bruijne M, Spreeuwenberg P, Wagner C. How effective are patient safety initiatives? A retrospective patient record review study of changes to patient safety over time. BMJ Qual Saf. 2015;24(9):561-71.

28. Borghans I, Heijink R, Kool T, Lagoe RJ, Westert GP. Benchmarking and reducing length of stay in Dutch hospitals. BMC Health Serv Res. 2008;8:220.

29. Hakkaart-Roijen L, Tan SS, Bouwmans CAM. Handleiding voor kostenonderzoek: Methoden en standaard kostprijzen voor economische evaluatie in de gezondheidszorg (in Dutch): CVZ. 2010.

30. Langelaan M, De Bruijne MC, Baines RJ, Broekens MA, Hammink K, Schilp J et al. Monitor Zorggerelateerde Schade 2011/2012: dossieronderzoek in Nederlandse ziekenhuizen (in Dutch). Amsterdam/Utrecht: EMGO+ Instituut/ VUmc, NIVEL. 2013

31. Twisk JW. Applied multilevel analysis: a practical guide: Cambridge University Press. 2006.

32. Forster AJ, Taljaard M, Oake N, Wilson K, Roth V, van Walraven C. The effect of hospital-acquired infection with Clostridium difficile on length of stay in hospital. CMAJ. 2012;184(1):37-42.

33. Allegranzi B, Pittet D. Role of hand hygiene in healthcare-associated infection prevention. J Hosp Infect. 2009;73(4):305-15.

\section{Submit your next manuscript to BioMed Central and we will help you at every step:}

- We accept pre-submission inquiries

- Our selector tool helps you to find the most relevant journal

- We provide round the clock customer support

- Convenient online submission

- Thorough peer review

- Inclusion in PubMed and all major indexing services

- Maximum visibility for your research

Submit your manuscript at www.biomedcentral.com/submit 